\section{Synthesis of Conjugated Nanohoops Containing Antiaromatic Units}<smiles>O=C1C2C=C(Br)C=CC2C2C(=O)c3ccc(Br)cc3C12</smiles>

9

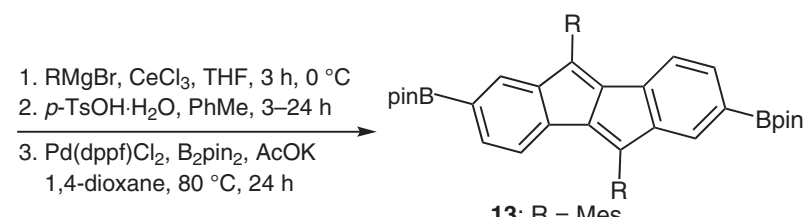

13: $\mathrm{R}=$ Mes

14: $\mathrm{R}=3,5-\left(\mathrm{CF}_{3}\right)_{2} \mathrm{C}_{6} \mathrm{H}_{3}$

15: $\mathrm{R}=n-\mathrm{Hex}$

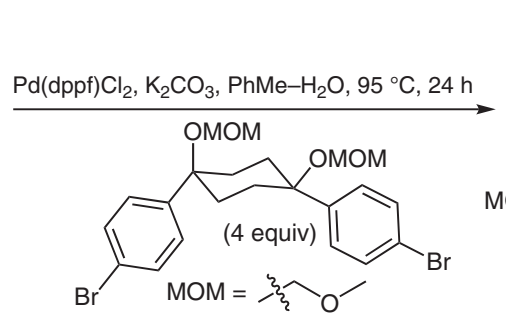

1. Ni(cod) $)_{2}, 2,2^{\prime}$-bipyridine, THF $65^{\circ} \mathrm{C}, 72 \mathrm{~h}$

2. $\mathrm{NaHSO}_{4}$, air, mesitylene-DMSO $155^{\circ} \mathrm{C}, 72 \mathrm{~h}$

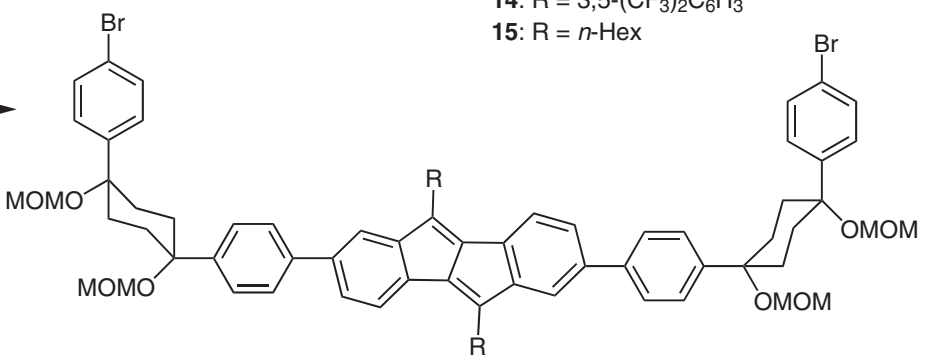

16: $\mathrm{R}=$ Mes

17: $\mathrm{R}=3,5-\left(\mathrm{CF}_{3}\right)_{2} \mathrm{C}_{6} \mathrm{H}_{3}$

18: $\mathrm{R}=n-\mathrm{Hex}$

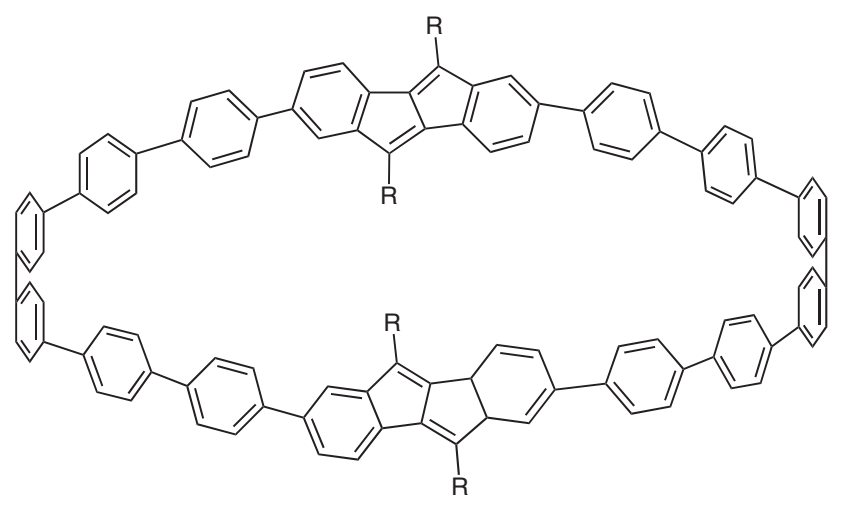

2: $\mathrm{R}=$ Mes

3: $\mathrm{R}=3,5-\left(\mathrm{CF}_{3}\right)_{2} \mathrm{C}_{6} \mathrm{H}_{3}$
Synthesis of

Materials and

Unnatural Products

\section{Key words}

conjugated

nanohoops

antiaromaticity

$\pi$-system
Significance: Conjugated nanohoops have attracted attention mainly because of the extensive investigation of cycloparaphenylenes in recently years. In their paper, Esser and co-workers synthesized conjugated nanohoops containing dibenzo[a,e]pentalene (DBP), which is a nonalternant hydrocarbon with antiaromatic character. With the incorporation of DBPs, the nanohoops exhibited ambipolar electrochemical behavior.
Comment: The conjugated nanohoops containing DBPs were synthesized in six steps including a nickel-mediated macrocyclization reaction. It is worth noting that since the DBP units were attached to electron-withdrawing substituents in the nanohoops, the antiaromatic character of the DBP was reduced. Furthermore, analysis showed that the frontier molecular orbitals were separated between the CPP and DBP units in the nanohoop. 